\title{
The Nitrogen Question from the Military Standpoint
}

\author{
Our Dependence Upon the Nitrate Supply for National Defense
}

\author{
By Charles E. Munroe, Professor of Chemistry, The George Washington University
}

THE invention of gunpowder afforded man a means of utilizing the energy of chemical separation in effecting propulsion and of more efficiently applying this form of energy in mining and quarrying. Through the discovery or invention of mercuric fulminate, the cellulose nitrates, the glyceryl nitrates, the nitro-substitution compounds, and the various explosive compositions made from these nitrates and nitro-compounds, man was enabled also to utilize the energy stored up in unstable molecules. History indicates that the invention of gunpowder was made where saltpeter, which is its ehief ingredient, was naturally most abundant and most easily obtained, but that, owing to the great value of gunpowder to man, its use and manufacture spread to the cooler and more humid countries, and it is in these countries that it and the other explosives enumerated have come to be which to show the increase in the use of powder throughwhich to show the increase in the use of powder through-
out the world, but some relative idea of this growth in recent years may be gained from Table 1, which sets forth the quantity, or value, or both, of the gunpowder, including, since 1860 , blasting powder also, produced in the United States in each census yea beginning with 1840.

The statisties for the world's production of the modern explosives are also not accessible, but an item contributing toward the assembling of this valuable information regarding the world's progress was given for dynation regarding the world's progress was given for dyna-
mite as sold from the several factories with which Alfred Nobel, the inventor of dynamite, was associated, though as there were, during the period covered, independent factories in Germany, in America, and probably in other countries, these figures, as set forth in Table 2 give only a relative idea of the growth of this industry.

Table 1.-Powder Produced in the United States.

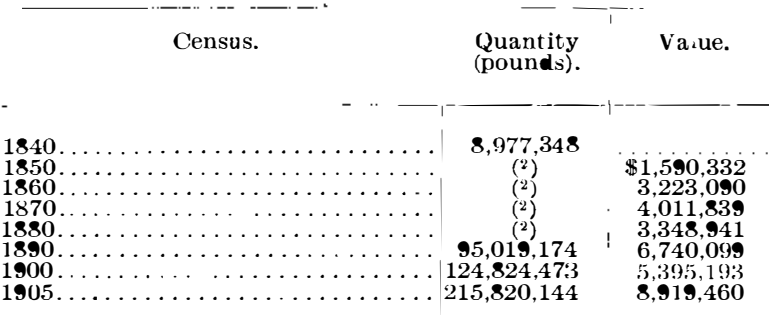

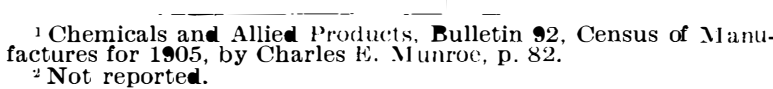

The most complete and detailed figures relative to the production of explosives to be found anywhere are those presented in the reports on the census of manufactures of the United States for 1900 and 1905, which are as follows, the gunpowder and blasting powder are as follows, the gunpowder and blasting powder
which were combined in Table 1 , being presented separately in Table 3.

Table 2.-Annual Sales of Dynamite from Nobel Factories. ${ }^{1}$

\begin{tabular}{|c|c|c|c|}
\hline Year. & Tons. & Year. & Tons. \\
\hline $\begin{array}{l}1867 \ldots \\
1868 \ldots \\
1869 \ldots \\
1870 \ldots \\
1871 \ldots \\
1872 \ldots \\
1873 \ldots\end{array}$ & $\begin{array}{r}78^{11} \\
184 \\
424 \\
785 \\
1,350 \\
2,050 \\
3,120\end{array}$ & $\begin{array}{l}1875 \ldots \\
1876 \ldots \\
1877 \ldots \\
1878 \ldots \\
1879 \ldots \\
1880 \ldots \\
1881 \ldots \\
1882 \ldots\end{array}$ & $\begin{array}{r}3,350 \\
4,000 \\
5,500 \\
6,200 \\
7,000 \\
7,500 \\
\$, 500 \\
9,500\end{array}$ \\
\hline
\end{tabular}

1 Notes on Nitroglycerin, Dynamite, and Blasting Gelatine, by
George Mc Roberts, Phil. Soc. Glasgow April 25, 1883 .

It is an interesting and important fact that, as with gunpowder so with all of the other explosives enumerated, a nitrogen-containing compound is employed in the manufacture of each and nitrogen remains as a component or constituent of each product. The quantity of nitrogen in one hundred parts of these explosives, together with its equivalent in real nitric acid and in sodium nitrate, is shown, together with other data relative to these explosives, in the following table:

In calculating the data for Table 4 the gunpowder is assumed to be composed of $\mathrm{KN}^{2}, 75$ per cent; C, 15 per cent; S, 10 per cent; and the blasting powder of NaN- ${ }^{3}, 74$ per cent; C, 16 per cent; S, 10 per cent; but variations from these compositions will be found in practice. However, it is believed that they represent very closely the averages of all commercial compositions so styled. Although a most important explosive, dynamite is omitted from the table because the wide variations in the character and quantities of the components of this mixture as it occurs in commerce render it impossible to properly represent it by an average formula, though it is usually admitted that on the * Reprinted from United States Naval Institute Proceedings,
vol. 35, No. 3. Copyrigle 1909 , by Philip R. Alger, secretary average dynamite contains 40 per cent of nitroglycerol. The wide variation in nitrogen contents occurs in the dope or absorbent, which may contain from no nitrogencontaining component whatever, as in the kieselguh dynamites, to 60 per cent of sodium nitrate in straight wood-pulp dynamites; and this last material may be wortly or wholly replaced by ammonium or potay he partly or wholly replaced by ammonium or potassium Because of a similar wide variation in their component the compositions made from picric acid, its salts, and other nitro-substitution compounds are also omitted.
Notwithstanding these omissions, it is believed that the Table 3.-Quantities and Values of Explosives Produced in the United States in the Census Years 1900 and 1905.

\begin{tabular}{|c|c|c|c|c|c|}
\hline & & 1900 & & & \\
\hline & & $\begin{array}{c}\text { Quintitity. } \\
\ldots . . .\end{array}$ & value. & Quantity. & Vallne. \\
\hline 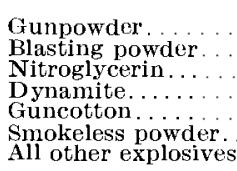 & 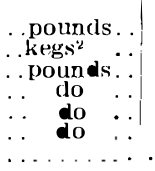 & $\begin{array}{c}5,450,773 \\
4.774,948 \\
35,280,4988^{3} \\
85,846,456 \\
2.988,176^{\circ} \\
3,053,126\end{array}$ & $\begin{array}{r}\$ 614,290 \\
4,780,903 \\
5,532,570 \\
8,247,22: 3 \\
1,473,619 \\
1,716,101 \\
6,493\end{array}$ & 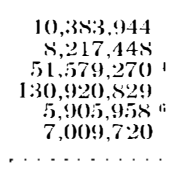 & $\begin{array}{r}\$ 1,541,48: 3 \\
7,377,977 \\
7,730,735 \\
12,900,19: 3 \\
2,435,1905 \\
4,406,477 \\
190,948\end{array}$ \\
\hline
\end{tabular}

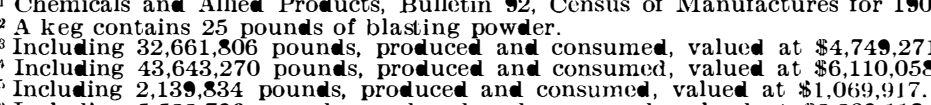

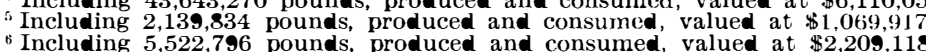

data set forth in the table may prove useful in the development and checking of the statisties of manufacture. But, unfortunately, owing to the different manners in which the nitrogen atoms are grouped, as regards the other atoms, in the molecules of the different kinds of explosives, no direct relation is to be observed between the properties and behavior of these different bodies and the percentages of nitrogen they contain and this want of relation becomes the more marked the larger the number of different nitrogen-containing substances that we consider. What, however, is emphasized by this presentation of data, is that the element nitrogen is a characteristic and important component of all explosives that have been accepted and used for military purposes.

From the time of the invention of gunpowder until the middle of the last century the only recognized available source of this nitrogen was India saltpeter which is the potassium nitrate, and which was obtained from the niter found or formed in soil or rocks. The production of nitrates in the soil or rocks is brought about usually through the agency of nitrif ying bacteria. about usually through the agency of nitrifying bacteria.
In order that the process of nitrification may go on In order that the process of nitrification may go on
there is required a supply of nitrogenous organic matter, there is required a supply of nitrogenous organic matter, definite limits, a limited amount of moisture, a supply of oxygen or air, complete or semi darkness, and th presence of the nitrifying organisms. The nitrification proceeds most rapidly at $100 \mathrm{deg}$. F. and within a few inches of the surface of soil or rock which is well aerated and moderately moist. When potash salts are present in sufficient quantity the potassium nitrate is produced, but the native niter usually consists largely of calcium nitrate with some magnesium nitrate and other salts. All of these nitrates are readily soluble in water and may therefore, after formation, be to a great extent washed away by frequent rainfalls, but where there is only a moderate amount of water present the solution may be brought to the surface by eapillarity, and as the water evaporates the nitrates will be left as an efflorescence on the surface of the soil or rock. It is
evident, therefore, that accumulations of niter will be evident, therefore, that accumulations of niter will be
largest in those localities where not only the best conditions for its production obtain, but where also it is least likely to be washed away after being formed. The native sources of supply are therefore found as efflorescences on the soil in semi-arid countries, in limestone caverns, where the remains and excreta of bats are the chief source of the organic matter, and about stables. Since the amount of niter procurable from these sources was limited it became necessary, as the demand for saltpeter increased, to resort to other sources of supply, and consequently niter plantations were established in many countries where, following the principles set forth above, the niter was formed and protected from the weather. Desortiaux, ${ }^{1}$ describes in detail the saltpeter plantations of Hungary, Switzerland, France, and Sweden. Such farms have been carried on in this country, especially in the Southern States during the country, especially in the Southern States during the of Selma, Alabama, to secure the necessary nitrogenous 1 Traité sur la poudre, les corps explosifs et la pyrotechnic,
vol. 1, pp. 15-117, 1878. were shipped in that year. Investigation has shown that this deposit extends for some 450 miles north and south in the arid plains which lie between the western slope of the Andes Mountains and the coastal range on the Pacific, at altitudes of from 3,600 to 13,000 feet and at distances of from 15 to 93 miles from the sea. The exploitation of this deposit has been pushed to such an extent that in the year ending December 31 , 1908 , there were shipped from the various South $A$ morican ports contiguous to this field 1,993,000 tons of the nitrate of soda, and because of the export taxes levied upon this material and the payments required for concessions to operate in this desert tract, this industry has been and still is a rich source of revenue to the Chilean Government. The extent to which this industry has grown and its rate of growth are clearly set forth in the following table prepared by F. V. Vergara, ${ }^{4}$ collector of customs at the port of Valparaiso:

Table 5.-Sodium Nitrate Exported from Chile, 1840-1903.

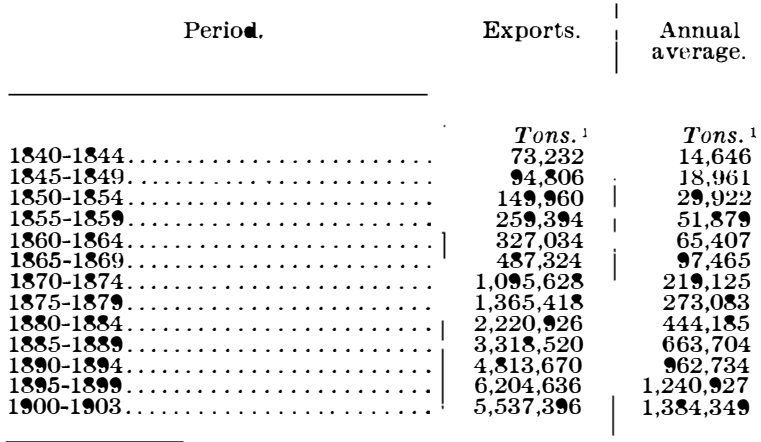

Metric tons of 2,204 pounds

This material was not only cheap and relatively abundant, but, as previously shown, ${ }^{5}$ the richest known source of oxygen for use in explosives. It is not surprising, therefore, that its use for this purpose has rapidly grown. Nitrate of soda was first used in blasting powder in 1856, and a patent for such a powder was issued to La Motte Dupont in 1857. During the census year 1905 there was produced in the United States 205,436,200 pounds of blasting powder, most of which was nitrate of soda powder, and large quantities of this powder were manufactured and consumed in Chile and other countries.

As nitrate of soda is quite deliquescent it is not suitable for direct use in the compounding of gunpowder, but early after becoming available in commerce it was made a source of manufacture of saltpeter. It was during the Crimean war (1854-55) that this industry was established in Germany, the sodium nitrate being converted into potassium sitrate by means of potassium earbonate obtained from the residues of sugar beets, and this assisted in the promotion of the beet-root sugar industry which Germany was seeking to foster. Singularly, about this time the now famous deposit

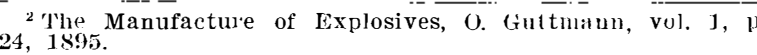



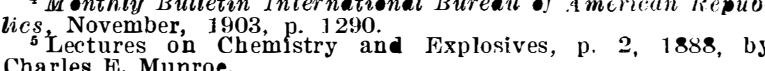


of potassium salts was discovered at Stassfurt, Germany. This town was noted for its salt works in the beginning of the nineteenth century, the source of supply being the natural brine from driven salt wells. With the utilization of rock-salt deposits in various localities, the price of salt was reduced to such a point that the Stassfurt works ceased to yield their former large revenue to the Prussian Government, and, with a view of making them again valuable, the Government began boring for rock salt in this locality in 1839 . In 1857 a shaft, which began in 1852 , reached, at a depth of 1,080 feet, a stratum of rock salt, but in doing so it passed through a heavy deposit of so-called "Abraum-salze" or refuse salts, which were then considered worthless. The "Abraum-salze" were found to consist largely of the minerals carnallite, which is a magnesium-potassium chloride; sylvite, which is potassium chloride; and kainite, which is a mixture of carnallite and magnesium
chloride, and these refuse salts are to-day the chief ehloride, and these refuse salts are to-day the chief
source of the world's supply of potashes and potassium source of the world's supply of potashes and potassiun
salts. Numerous uses have been found for them, not salts. Numerous uses have been found for them, not
the least interesting of which is the production of saltpeter from the metathesis of the Chile nitrate with the Stassfurt sylvite or earnallite. In the United States alone there were produced 14,468,000 pounds of potassium nitrate by this means during the census year 1905, and this operation has been conducted here for many years. It is by such means that the Chile deposits many years. It is by such means that the Chile deposits use in sporting and military powders.

It has already been shown that the manufacture of dynamite consumes large quantities of nitrate of soda, and it has been also shown that the modern explosives, pyroxylin, guncotton, picric acid, and nitroglycerol, sodium nitrate, or of any other nitrate as a source of the required nitron an gunpowder dos, while the required nitrogen, than gunpowder does, while mercuric fulminate requires nearly as much. It may,
therefore, be safely asserted that but for the discovery and exploitation of the nitrate fields of Chile the explosives industry, as it is known to-day, would have been impossible, and the developments in mining and transportation which have characterized the last half century could not have been made. That is, the condition of eivilization amid which we now live could not have been attained.

Yet the explosives industry is but one of several in which nitrate of soda is used. The relative quantities used in various countries differ. Unfortunately no detailed and accurate statistics can be had except for the United States. Omitting the minor industries of enameling, fluxing in metallurgy, pickling of meats and fish, and the manufacture of subordinate chemicals in which approximately 23,926 short tons were used during the census year 1900, and 67,937 short tons in 1905, follows:

Table 6.-Nitrate of Soda Consumed in the United States by Establishments Classed as Follows.

Class $1900 . \quad 1905$.

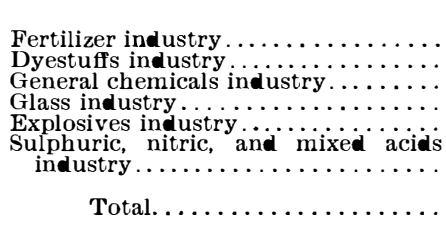

\begin{tabular}{r|r} 
Short tons. & Short tons. \\
19,518 & 42,213 \\
223 & 213 \\
35,990 & 38,048 \\
10,770 & 11,915 \\
$\mathbf{8 8 , 5 2 4}$ & 133,034 \\
27,406 & 29,301 \\
182,431 & $-254,772$
\end{tabular}

It thus appears that of the total available supply of nitrate of soda in the United States but 42.90 per cent was used at the census of 1900 , and 41.22 per cent at the census of 1905, in explosives factories, and of this a notable portion was used in the manufacture of saltpeter which was sold for other uses in the arts. While all the industries enumerated show a growing demand, the largest increase in any single industry is found in the fertilizer industry, where 22,695 tons, or 116.2 pe cent more of nitrate were used at the census of 1905 than were used at that of 1900 .

While no detailed statement of the consumption of nitrate of soda elsewhere is available, there is issued semi-annually by W. Montgomery \& Company (Limited) of 63 Mark Lane, London, a statement of the total shipments, consumption, stocks, and prices of this shipments, consumption, stocks, and prices of this
article during a considerable period, and the following article during a considerable period, and the following
data are derived from their circular statement for data are derived from

Table 7.-Consumption of Nitrate of Soda in 1908

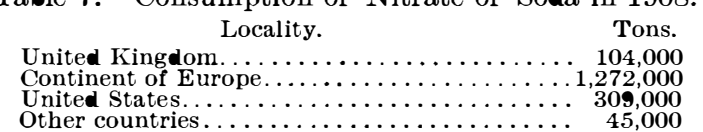

$$
\text { Total..... }
$$



g9,000; Continent of Europe, 1,233, o00; United States,
315,000 ; other countries, 55,000; total, $1,702,000$ tons.
From these data the percentage of the total consumption
for the United States is 18.51 .

¿Journal of Industrial and Chemical Engineering, I, 298,
1909, by Charles E. Munroe.

\begin{tabular}{|c|c|c|c|c|c|c|}
\hline \multirow[t]{2}{*}{ Explosive. } & $\begin{array}{l}\text { Acid components } \\
\text { of nitrating } \\
\text { mixture. }\end{array}$ & \multirow{2}{*}{$\begin{array}{l}\text { (3) } \\
\text { Weight } \\
\text { of aciil } \\
\text { per } 100 \\
\text { of raw } \\
\text { mate- } \\
\text { rial. }\end{array}$} & \multirow{2}{*}{$\begin{array}{l}\text { (4) } 1 \\
\text { Weight } \\
\text { of } \\
\text { product } \\
\text { per } 100 \text { of } \\
\text { raw mate- } \\
\text { rial. }\end{array}$} & \multirow{2}{*}{$\begin{array}{l}(5) \\
\text { Per cent } \\
\text { of con- } \\
\text { tained } \\
\text { nitro- } \\
\text { gen. }\end{array}$} & \multirow{2}{*}{$\begin{array}{l}\text { (6) } \\
\text { Equiva- } \\
\text { lent of } \\
\text { HNO } \\
\text { in } 100 \\
\text { parts of } \\
\text { product. }\end{array}$} & \multirow{2}{*}{$\begin{array}{l}\text { (7) } \\
\text { Equiva- } \\
\text { lent of } \\
\text { NaN O } \\
\text { in } 100 \\
\text { parts of } \\
\text { product. }\end{array}$} \\
\hline & $\mathrm{H}_{2}{\stackrel{(1)}{\mathrm{SO}_{4}}}_{4}^{(2)} \mathrm{HNO}_{3}$ & & & & & \\
\hline 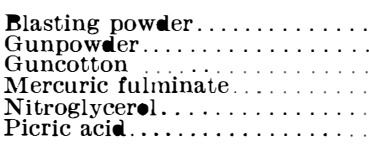 & $\begin{array}{ll}78.6 & 21.0 \\
61.5 & 65.0 \\
26.6 & 35.5\end{array}$ & $\begin{array}{r}1,200.0 \\
1,200.0 \\
489.7 \\
400.0\end{array}$ & $\begin{array}{l}100 \\
100 \\
150 \\
120 \\
228 \\
220\end{array}$ & $\begin{array}{l}12.20 \\
10.40 \\
13.40 \\
9.85 \\
18.50 \\
18.30\end{array}$ & $\begin{array}{l}54.85 \\
46.74 \\
60.30 \\
44.33 \\
83.25 \\
82.35\end{array}$ & $\begin{array}{r}74.00 \\
63.00 \\
81.34 \\
59.79 \\
112.30 \\
111.08\end{array}$ \\
\hline Pyroxylin for S. P... & 56.0 & $\left({ }^{4} 5,000.0\right)$ & 145 & 12.50 & 56.25 & 75. 88 \\
\hline
\end{tabular}

Table 4.-Per Cent of Nitrogen in Certain of the More Important Explosives.

Factory yields.
Using artificiai refrigeration, vide Census Bulletin No. 92 of 1905
Nitrating in pots.

From this it appears that of the total consumption of the year but 17.8 per cent was consumed in the United States. Analyzing the statement for the previous eight years, it appears that of the total, that consumed in the United States was, in 1900, 12.6 per cent; 1901 14.1 per cent; $1902,16.9$ per cent; $1903,18.76$ per cent; 1904, 19 per cent; 1905, 19.9 per cent; 1906, 21.7 per cent; 1907, 21.1 per cent; so that there wa a steady increase in the proportion of the total consumed in the United States up to 1906, but that for the next two years there was a drop such that in 1908 our proportionate consumption was less than for any year since 1902 .

It is commonly understood that a much larger percentage of the Chilean nitrate is used in agriculture in Europe than is used in this industry in the United States, and that the proportion is steadily increasing. the teaching of Baron von Liebig, whose views have become gradually disseminated among the farmers. A marked impetus was given to this use of the Chilea nitrate by the remarkable address made by Sir Willian Crookes before the British Association for the Advancement of Science in 1898, when, in dealing with the problem of meeting the rapidly increasing demand for food, he pointed out that while the average yield of wheat was but 12.7 bushels per acre it had been demonby the use of $1 \frac{1}{2}$ hundredweight of nitrate of soda on by the use of $11 / 2 \mathrm{~h}$

This increasing use, however, tends to exhaust the supply. Crookes estimated that if the nitrate were used over the whole area under cultivation at the rate he proposed, the Chilean deposits would be exhausted in four years. Vergara estimated that at the rate that the nitrate had been mined and exported between 1840 and 1903, as shown in Table 5, the Chilean deposits would be exhausted by 1938. Albert Hale, however, in a more recent review of the situation, ${ }^{7}$ points out that these estimates were based on the contents of the deposits then known in the province of Tarapaca, and the extent to which they could be profitably worked and states that deposits of such magnitude have since been discovered in the provinces of Antofogasta and Atacama, and the processes of recovery of the nitrate
from low-grade ore (caliche) have been so improved that, at a rate of consumption of 5,000,000 tons annually, which he expects will be the normal demand in a few years, there is enough nitrate in these deposits to last three hundred years.

This is a more encouraging outlook, but, nevertheless, from what has been said it is evident that the world has for long been largely dependent on these Chilean deposits for the greater part of its supply of nitrat and the substances derived from it. In time of prolonged war, in ease nitrate has become contraband, policy of niter farming, or, as our Navy Department has done since 1863, have accumulated in advance con-
siderable stores of niter, and this condition would have siderable stores of niter, and this condition would have
continued to hold but for important advances recently made in the production of nitrate from atmospheric nitrogen, and through other developments in chemistry. We have in our atmosphere an abundant supply of this element. It is estimated that the air over each acre of ground contains 33,880 gross tons of nitrogen. It is, however, free, and to be available for use it must be combined. The methods for effecting the fixation of
this nitrogen have proceeded along three lines: (1) The this nitrogen have proceeded along three lines: (1) The
production of nitric acid and nitrates; (2) the producproduction of nitric acid and nitrates; (2) the produc-
tion of eyanides; and (3) the production of amids, and the first and last have now been brought to commercial success.

As early as 1755 Priestly had noted that nitrogen compounds were formed when electric sparks were passed through air, and not long after Cavendish produced saltpeter by absorbing air, so treated, in caustic potash solution. Repeated attempts have been made potash solution. Repeated attempts have been made
since high potential currents have become readily available to utilize this method and an establishment was erected at Niagara Falls, by the Atmospheric Products Company, to operate the Bradley and Lovejoy process. ? Bull. International Bureau of American Republics, p. 27,
July, 1908 .
This method, for which a United States patent was ranted September 30th, 1902, consisted in producing in the air a flaming electric are of minimum volume by the rapid rotation of electrodes carrying high tension currents, but while it yielded nitric acid the method proved too eostly.

A more successful device was shortly after put into operation by Birkeland and Eyde at Nottoden, Norway, and it has been in operation ever since. In this the flaming ares produced by high tension currents were made to move to and fro through the air within the apparatus by exposure to powerful magnets. This apparatus by exposure to powerful magnets. This
apparatus was characterized by a narrow chamber through which the air was passed and within which the electrodes, placed near together, were arranged between the poles of a strong magnet and at right angles to these poles. A disk-shaped or deflected electric are was thus obtained perpendicular to the lines of force of the magnetic field. Three such furnaces at Nottoden, using 500 kilowatts and 5,000 volts, gave deflected ares about 3 feet in diameter. The nitrogen oxides formed were quite dilute and they were carried oxides formed were quite dilute and they were carried
to absorption towers where, by contact with milk of lime, calcium nitrate was formed, the product being eventually converted into basic calcium nitrate for use as a fertilizer. According to $\bullet$. N. Witt,' with this apparatus an output of 500 to 600 kilos of nitric acid per kilowatt year can be regularly maintained.

A still more efficient form of furnace is that devised

by Dr. Otto Schoenherr for the Badische Anilin and Soda Fabrik. From his lecture, delivered June 11th, 1908, before the Verein Deutscher Chemiker at Jena, it appears that what is sought in these processes is to burn the nitrogen with the oxygen of the air. To accomplish this to any satisfactory degree the gases must be exposed to a temperature of 3,000 deg. C. (5,432 deg.F.) and upward. To prevent the decomposition of the product formed it must be immediately removed to a cooler region. This Birkeland and Eyde accomplish through moving the are to and fro by the aid of magnets, while Shoenherr effects it by imparting to his air a gyratory motion about his elongated arc. His apparatus consists of a long iron tube in which an are 5 meters (16.4 feet) in length, produced by an alternating current, is maintained constantly, the energy required being about 600 horse-power and the alternations being 50 per second. Air, which has been heated to 500 deg. C. (932 deg. F.) by the hot discharge of gases, is blown tangentially into this tube so that it surrounds the are spirally in its passage through the tube. This prevents the deflection of the are, permits of the maximum exposure of the air to the heat from the arc, and promptly sweeps the heated and reacting air to the cooler portion of the tube and beyond. A 2,000 horse-power plant of this character has been in operation at Christiansand, Norway, since the autumn of 1907 , and its success has been such that the building of a 120,000 horse-power plant of this character has been undertaken at Rukwan Falls, Norway. The advantage claimed for this process is that it gives a good yield of concentrated gas.

The third method for the fixation of atmospheric nitrogen referred to above has been brought to a successful realization by Frank and Caro in their production of calcium cyanamid mixed with carbon or "lime nitrogen," or "nitrolim," as it is more recently called. This is produced 10 by heating calcium carbide in vertical iron retorts in an atmosphere of nitrogen, when the calcium cyanamid, mixed with carbon, is formed according to the following equation:

$$
\mathrm{CaC}_{2}+\mathrm{N}_{2} \rightarrow \mathrm{CaCN}_{2}+\mathrm{C} \text {. }
$$

The nitrogen is obtained by liquefying the air and separating its constituents by fractional distillation, or by passing the air over heated copper, by which the A plant with a capacity of nearly 4,000 tons per year was started at Piano d' Orta, Italy, in 1906, and with such success that the production was carried in 1908

8 The Electrochemical l'roblem of the lixation of Nitrogen,
Phillippe A. Guye, J. Soc. Chem. Ind. 25, 5C. 1906 .

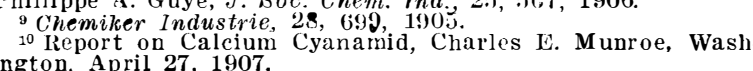
ington, April 27, 2907 . Census of Manufactures, 1905, Coke,
p. 18, by Charles E.' Munroe. 
to over 40,000 tons per annum in five plants, with other building. 'The material as produced is used directly a a fertilizer, but it is a simple matter to obtain ammonia from it and by a contact process this may be directly converted into nitric acid.

Yet another indirect source of supply of nitric acid and, therefore, of saltpeter is found in the manufacture of coke, for an important product of the by-product coke industry is ammonia, which is obtained usually nowadays as ammonium sulphate. I have elsewhere shown" that 15,773 tons of ammonium sulphate wer produced in this country in 1905 . But as only $3,317,58$ tons of the $37,376,251$ tons of coal coked in the census year were coked in by-product ovens it was possible, had all been so treated, to have obtained 359,560 tons of ammonium sulphate, all of which if desired could have been converted into nitric acid for use in the have been converted into nitric acid for use in the
manufacture of saltpeter or of any desired variety of explosive.

From this account of recent chemical progress it is avirent that it is possible to conduct a prolonged wa he soil on which the people depend and constantly increasing demand for nitrogen compounds in agriculture and manufacture, this country has reached a potential degree of independence, as regards its supply of nitrogen compound for military uses, such as it never before enjoyed, so that it needs hereafter to consider foreign sources of supply only from the economic standpoint. However I desire to say regarding the plants for the fixation of nitrogen what I have repeatedly advised regarding plants for the manufacture of explosives, viz., that it is a wise policy for our Government to foster, and in a measure supervise, these manufacturing operations, and to look to it that plants for these purposes are so strateto look to it that plants for these purposes are so strate-
getically located throughout the country as to be reasongetically located throughout the country as to be reason-
ably well protected from attack, so that they may serve the military establishment in case of foreign invasion from any quarter or of internal uprisings in any locality.

On the Proper Motions of the Fixed Stars

By W. Doerereck, Ph.D., F.R.A.S., M.R.l.A

HALLEY found that some of the brightest fixed star had changed their places since they had been observed by the ancient Greeks, and such changes are
so obvious as to be recognized on ancient coins. Sir William Herschel, in 1783, arrived at the conclusion that a relative motion of the sun among the fixed stars in the direction of a point situated near $\lambda$ Her culis would account for the greater part of these proper motions: the motion of the sun towards the "apex" must cause the fixed stars in half the sky to apparently move away from that point, and in the other half of the sky to move towards the diametr cally opposite point, the "anti-apex." Since then a great many astronomers have determined the situation of the "apex," but the results do not agree very well, especially as regards the declination. Bessel investigated the matter and declared himself dissatisfied with the evidence. When the direction of the proper motion of a fixed star has been ascertained, great circle laid through the positions of the star observed at two epochs is thereby determined, and if the great circles belonging to different stars intersect in a point (the apex), it is easy to see that the poles of these great circles must lie on another great circle, of which the apex is the pole. Bessel found that the poles do not lie on or near a great circle, but are scattered over the sky. Kobold, the editor of the Astronomische Nachrichten, who some year's ago took up Bessel's invesigations, proceeds as fol lows. He imagines the celestial sphere inscribed in a cube which touches the sphere at the two poles and at four points on the Equator. He supposes the eye of the observer situated in the center of the sphere and any great circle on the sphere is then projected as a straight line on one or more of the faces of the cube. Kobold had already used maps made on this principle in determining radiants of shooting stars principle in determining radiants of shooting stars, and the writer had subsequently, in Hongkong, used
similar maps for the same purpose. Kobold projected the poles of a great number of proper motions in such maps. Those tbat correspond to proper motions interserting in the apex sbould lie on a straight line corresponding to the great circle of which the apex is the pole, but that is not clearly shown on the maps.

Kapteyn, who has the merit of having originated many hypotheses that appear destined to aid greatly in the astronomy of fixed stars, solves the difficulty by accounting for a great number of proper motion on the supposition that there are two distinct apices both close to the galaxy. It had, indeed, in course of years, become the general impression that the galaxy is made up not of isolated heavenly bodies, but of conglomerate of clusters of stars and nebulæ. Ther was, therefore, nothing extraordinary in the circum-
stance that the star's bellonging to two clusters did

* From Knoulcloe. not move in the same direction. Kapteyn's hypothesis has been examined at the Greenwich Observatory and confirmed there by the independent evidence of proper molions, other than those used by Kepteyn. It has been connrmed also at the lape of liood hupe. It has been to some extent confirmed by spectroscopic evidence at the Cape Observatory and at the Lick bservatory.

The speed in miles with which a star is moving towards or away from the earth can be measured in the spectrum, the wave-length of the lines being respectively shortened or lengthened, and it is found hat the stars on opposite sides of the sky indicate a general drift, or even two drifts; but the objects used should be evenly distributed over the whole sky, and the spectra of only a few faint stars are known with sufficient accuracy for this purpose.

Meantime other radiants have been found. Boss, edicor of the Astronomical Journal, has shown that the Hyades form a greater cluster moving in parallel lines towards a certain radiant point. Another ap parently (but perhaps only apparently) much larger cluster, which has been investigated at the Potsdam Observatory, contains the stars in the Great Bear Sirius, and other bright stars.

As mentioned above, the spectroscope enables as tronomers to measure the motion of a heavenly body in the line of sight in miles per hour. The proper motion, expressed in seconds of arc, shows how much it is moving in the line perpendicular to the line of sight. When the direction of motion in space is known, then the parallax is at once obtained from these two quantities, and that direction is given by the radiant. Parallaxes of fixed stars are more ac curately determined in this way than by any other method. Numerous results have been obtained. Ther show that the magnitude of a star forms no guide to its distance from us. Stars of different intrinsic brightness are mixed in space. Therefore, it would be no wonder if some of the small telescopic stars should turn out to be compartively near the Solar System. Proper motions have hitherto been determined by comparing positions recently deter mined by the meridian circle with older results. Burnham, at the Yerkes Observatory, has of late years determined a number of proper motions by aid of micrometric measures compared with previous measures made by Struve, Sir Robert Ball, and others. In those cases where his results differ from the result of meridian work, the difference is probably caused by hitherto unsuspected proper motions of faint stars, which it will be possible to determine by future micrometric measures compared with Burn ham's observations. A.t Heidelberg proper motions of faint stars are discovered by simp!y looking in a stereoscope at photographic plates of the same part of the sky taken several years apart. Turner has discovered large proper motions of stars as faint as the eleventh magnitude marked on photographic plates, and states that stars with proper motions greater than fifteen seconds per century are scattered with no sensible reference to the galaxy.

It may be asked what becomes of Herschel's expianation of the apex caused by the sun's proper motion when there are not one but many apices. It should be kept in mind that all motion is relative, and it is quite legitimate to attribute the apex of the cluster that contains the largest number of stars to the proper motion of the sun. Boss has lately dis. cussed about six thousand proper motions, and ho determines the apex without taking in o account the existence of different systems, and also without ex. cluding any objects.

It appears that all the radiants so far found lie near the galaxy, and it is much easier to determine additional radiants on the supposition that they all lie near the galaxy, than if they were scattered over the sky. If the pole of the galaxy is projected on Kobold's maps, and also the straight line (or rather lines) corresponding to the great circle of the galaxy, any straight lines from the projected pole to any point on the projected galaxy represents a great circle perpendicular upon the galaxy, and the projected poles of proper motions that lie near this line indicate stars the radiant of whose proper motions is the pole of the galactic meridian in question. By investigating the proper motions all round the sky in this manner it should be easy to discover all the radiants that lie near the galaxy.

Kapteyn, on the supposition that there are only two radiants, explains these as being caused by stars moving in two diametrically opposite directions, and the fact that they do not appear to be diametrically opposite he explains by combining the proper motion of the sun with each of them. In this way the dirention of the sun's proper motion is determined, but it is seen that the sun belongs to neither of the clusters. However, there are probably more than two star streams, and there is so far no reason to suppose that they move in exactly opposite directions.
It is conceivable that two globular clusters might attract each other, approach, and pass through to the opposite side. When they had reached the same dis. lance apart on the other side, they would stop, and their motion would be reversed. The period of the swing of such a pendulum would exceed millions of years. But when the enormous distances between the stars are taken into account, and their relatively insignificant sizes, the forces are found too insignificant to account for existing proper motions. The energy of runaway stars cannot be derived from attractions between fixed stars or clusters: it may be due to explosions.

As all observations of heavenly bodies are made by comparison with positions of fixed stars, the accurate determination of the proper motions of the latter may be said to be in some sense the most important object of astronomical observation. Several astronomers, especially Porter in Cincinnati, have devoted their energies to the discovery and determination of proper motions. An international co-operation between ob. servatories in all parts of the world is being ar ranged to make a determination with the utmost accuracy of the positions of a very great number of fixed stars evenly distributed over the sky to serve as standards for determining the positions of faint stars recorded on photographic plates. But however perfectly the catalogue embodying the results of such co-operation may reflect the actual situation in tbe sky of the stars it contains, it must in a few years become quite inaccurate as the stars change tbeir places, and for the determination of these changes the catalogue must rely on observations made in tbe past, so that the old observations, far from being superseded, gain in importance; and the older they are, the more important it becomes to take them nto consideration.

Plate for Indexing in Degrees.

Ат one time it became necessary to affix an indexing plate to a machine so as to be able to set a pointer at any one of the 360 degrees of a circle. The ratchet $A$ was not large enough to allow cutting 360 teeth in it, as these teeth had to withstand a moderate strain ing due to a flat coiled spring not shown in the illustration. Accordingly 120 divisions were provided

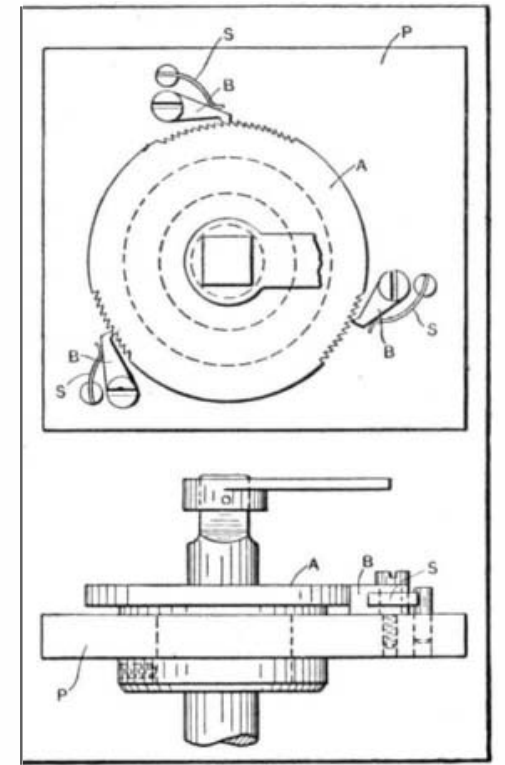

Plate which, by the Aid of Pawls of Unequal Lengths, indexes to Degrees.

in the ratchet and the pawls 3 were made so that they differed in length by $1 / 3$ the distance between wo of the ratchet teeth, or in other words by $1 / 3$ the pitch of the teeth. The action of the pawls is, there ore, consecutive; No. 1 first engages the ratchet, the if the pointer is moved $1 / 360$ of a revolution, or one degree, No. 2 engages and so on. The pawls are kept in engagement with the ratchet by means of the flat steel springs $S$, as shown. Tbe whole fixture is sul, ported on the plate $P$, which is part of the machine.Machinery.

\section{TABLE OF CONTENTS}

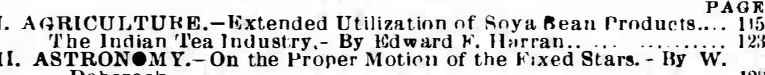

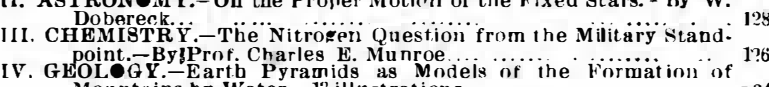

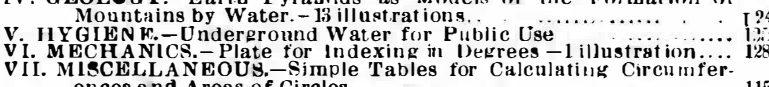



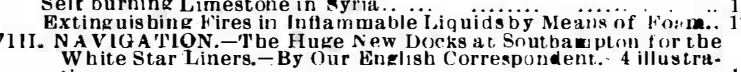

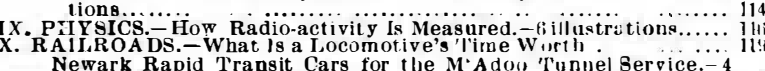

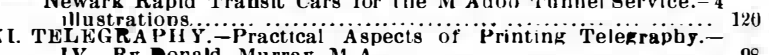



